\title{
Estimation of genetic parameters for dairy traits and somatic cell score in the first 3 parities using a random regression test-day model in French Alpine goats
}

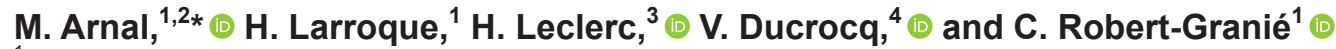 \\ ${ }^{1}$ GenPhySE, Université de Toulouse, INRAE, ENVT, F-31326, Castanet Tolosan, France \\ ${ }^{2}$ Institut de l'Elevage, Chemin de Borde Rouge, 31326 Castanet-Tolosan cedex, France \\ ${ }^{3}$ Institut de l'Elevage, INRAE UMR1313 GABI, 78350 Jouy-en-Josas, France \\ ${ }^{4}$ UMR1313 GABI, INRAE, AgroParisTech, Université Paris-Saclay, 78350 Jouy-en-Josas, France
}

\section{ABSTRACT}

Lactation curve shape can affect an animal's health, feed requirements, and milk production throughout the year. We implemented a random regression model for the genetic evaluation of lactation curve shapes of dairy traits in French Alpine goats for their first 3 parities. Milk, fat, and protein yields, fat and protein contents, somatic cell score, and fat/protein ratio were considered. The data consisted of test-day records from 49,849 first lactation Alpine goats during their first 3 lactations. The reference model used a Legendre polynomial of order 2 for each parity to describe the genetic and permanent environmental effects, and was compared with a model that combined the second and third parities. A rank reduction of the variance-covariance matrix was also performed using an eigenvalue decomposition for each parity from the 2 models. Genetic parameters were consistent between the models tested. With a reduction to rank 2 and combining the second and third parities, the first 2 principal components correctly summarized the genetic variability of milk yield level and persistency, with a near-nil correlation between the 2, and with a much shorter computation time than the reference model. A favorable correlation of +0.43 between milk yield persistency and fat/protein ratio persistency at the beginning of the lactation was found from buck estimated breeding values.

Key words: random regression model, reduced rank matrix, genetic parameter estimation, persistency, dairy goat

\section{INTRODUCTION}

Random regression models (RRM) are used for genetic evaluations of test-day (TD) milk production in

Received August 19, 2019.

Accepted January 7, 2020.

*Corresponding author: mathieu.arnal@idele.fr dairy goats worldwide (Zumbach et al., 2008; Menéndez-Buxadera et al., 2010; Mucha et al., 2014). Random regression models allow more accurate breeding value predictions and fit the variability of environmental effects on lactation more closely (Schaeffer and Jamrozik, 2008).

Random regression models allow the prediction of EBV for lactation persistency, based on the variation of genetic effects on lactation. A persistent animal is defined as one producing on average less milk at the beginning of lactation than animals with similar overall production, but more at the end (Cole and VanRaden, 2006). Lactation persistency interests dairy producers because the shape of the lactation curve affects the distribution of the farm's milk production during the year. In dairy cattle, several authors (Buttchereit et al., 2011; Jamrozik and Schaeffer, 2012; Koeck et al., 2013; Negussie et al., 2013) studied the fat/protein ratio (FPR) throughout lactation with an RRM. They showed that a high FPR at the beginning of the lactation was associated with a negative energy balance, subclinical mastitis, and impaired fertility, and suggested that selecting on this criterion could help avoid these adverse traits.

In France, the implementation of an RRM in dairy goats has been studied in first parity in Alpine and in Saanen breeds (Arnal et al., 2019). However, in Germany, Zumbach et al. (2008) reported an average genetic correlation of 0.64 for milk yield between the first and second lactations, of 0.46 between the first and third lactations, and of 0.75 between second and third lactations in German breeds of dairy goats. From first to fourth parity, the goats produced more milk on average, but their lactations were less persistent in Alpine and in Saanen breeds (Arnal et al., 2018). This highlights in particular the marked difference in lactation production potential between goats in successive parities. An RRM for the first 3 parities therefore needs to be developed to correctly evaluate French goats throughout their lives. 
Table 1. Number of test-day records and lactations by parity in the Alpine breed

\begin{tabular}{lrrr}
\hline & \multicolumn{3}{c}{ Parity } \\
\cline { 2 - 4 } Item & \multicolumn{1}{c}{1} & \multicolumn{1}{c}{2} & \multicolumn{1}{c}{3} \\
\hline Test-day records & 318,612 & 225,658 & 148,473 \\
Lactations & 49,849 & 34,859 & 23,207 \\
\hline
\end{tabular}

One disadvantage of an RRM is its long computing time. However, the relatively high genetic correlation between second and third parity reported by Zumbach et al. (2008), together with those found by Leclerc (2008) in French dairy cattle, means that these 2 parities could be modeled together. With eigendecomposition, the rank of the variance-covariance matrix can be reduced by ignoring the contribution of the smallest eigenvalues (van der Werf et al., 1998; Druet et al., 2003). Eigendecomposition and combining second and third parities would save computing time by reducing the number of genetic and permanent environment regression coefficients to be estimated.

This study set out to estimate genetic parameters for milk, fat and protein yields, and fat and protein contents, SCS, and FPR using an RRM with Legendre polynomial (LEG) functions, with and without rank reductions, and with and without combining second and third parities, to obtain EBV for French Alpine dairy goats in their first 3 parities.

\section{MATERIALS AND METHODS}

\section{Data}

The data consisted of 692,743 TD records from 49,849 Alpine goats from the French North-West region collected between 1995 and 2015. The pedigree consisted of 98,075 animals. When possible, goats were followed during their first 3 parities. The details of the distribution of TD records and lactations per parity are given in Table 1. Each lactation included at least 4 TD between DIM 7 and DIM 270. The lactation had to last for at least $180 \mathrm{~d}$. Goats were milked twice a day and their records were summed to obtain their daily production. More than 5 animals per herd per parity and per test date were required. The sires had to be AI bucks and to have at least 20 progeny each in the data set. There were 486 . The dams of the goats had to be known. The first lactation had to be available to study the subsequent parities. The traits analyzed were milk yield, fat yield, protein yield, fat content, protein content, SCS, and FPR. The SCS were calculated from SCC after Wiggans and Shook (1987).

\section{First to Third Parity}

Legendre Polynomial. A random regression model used in the first parity, described in Arnal et al. (2019), was extended to the first 3 parities. The 3 parities were analyzed simultaneously in a sort of multiple-lactations model. The genetic and permanent environmental effects were modeled by a Legendre polynomial of order 2 for each parity (LEG_FT):

$$
\begin{aligned}
& y_{t r s i j k l m d g n}=H T D_{t r i}+A_{t j k}+M_{t r j l}+D_{t r j m}+\sum_{o=1}^{6} \theta_{t k o} N_{(o, d)} \\
& +\sum_{o=1}^{6} \tau_{t r l o} N_{(o, d)}+\sum_{o=1}^{6} \pi_{t r m o} N_{(o, d)}+\sum_{o=1}^{4} \gamma_{t s o} M_{(o, g)}+\sum_{o=1}^{2} a_{t r n o} \varphi_{(o, d)} \\
& +\sum_{o=1}^{2} p_{t r n o} \varphi_{(o, d)}+e_{t r s i j k l m d g n},
\end{aligned}
$$

where $y_{t r i j i k l m d g n}$ is the observation for trait $t$ (milk yield, fat yield, protein yield, fat content, protein content, SCS, FPR $)$ of DIM $d(7, \ldots, 270)$ of goat $n$ carrying a kid for $g$ day $(\mathrm{s})(0, \ldots, 100)$, in production year $j(1995, \ldots$, $2015)$, in parity $r(1,2,3)$, in parity class $s$ [primiparous (P) or multiparous (M)], belonging to kidding age class $k$ [7 classes for first lactation (in months): $9-11,12,13,14,15,16,+17 ; 6$ classes for second lactation: 21-23, 24, 25, 26, 27, +28; 6 classes for third lactation: 31-35, 36, 37, 38, 39, +40], kidding month class $l$ (7 classes: January, February, March-April-May, June-July-August-September, October, November, December), class $m$ of dry period length $\{6$ classes (days): [First parity], [0,50], ]50,75], ]75,100], ]100,125], 125+\}, and herd $\times$ test-date class $i$. $H T D_{t r i}$ is the fixed effect for the herd test-date; $A_{t j k}$ is the fixed effect for the age at kidding; $M_{t r j l}$ is the fixed effect for the kidding period; $D_{t r j m}$ is the fixed effect for length of the dry period; $\theta_{t k o}, \tau_{t r l o}, \pi_{t r m o}$, and $\gamma_{t s o}$ are fixed regression coefficients for age at kidding, the kidding month, dry period length, and gestation stage, respectively; $N_{(o, d)}$ 
is the $o$ th covariate at time $d$ of a cubic natural spline function with 6 knots at $d=7,20,50,110,190,270 ; M_{(o, g)}$ is the oth covariate at time $d$ of a cubic natural spline function with 4 knots at $d=31,53,76,100$ (between $g=$ 0 and $g=30$, the coefficients were taken as equal to 0 ; if the gestation stage was greater than 100, it was taken as equal to 100); $a_{\text {trno }}$ and $p_{\text {trno }}$ are, respectively, the random additive genetic and permanent environmental regression coefficients for the oth term of a Legendre polynomial of order $q, \varphi_{(o, d)}$ is the value of the oth term of the Legendre polynomial at time $d$, and $e_{\text {trsijklmdgn }}$ is the residual term. The model assumed heterogeneous residual variances modeled with 9 classes within each parity: [7, 35], [36, 64], [65, 93], [94, 122], [123, 151], [152, 180], [181, 209], [210, 238], [239, 270].

The genetic variance-covariance matrix $(\mathbf{C})$ for LEG_FT was

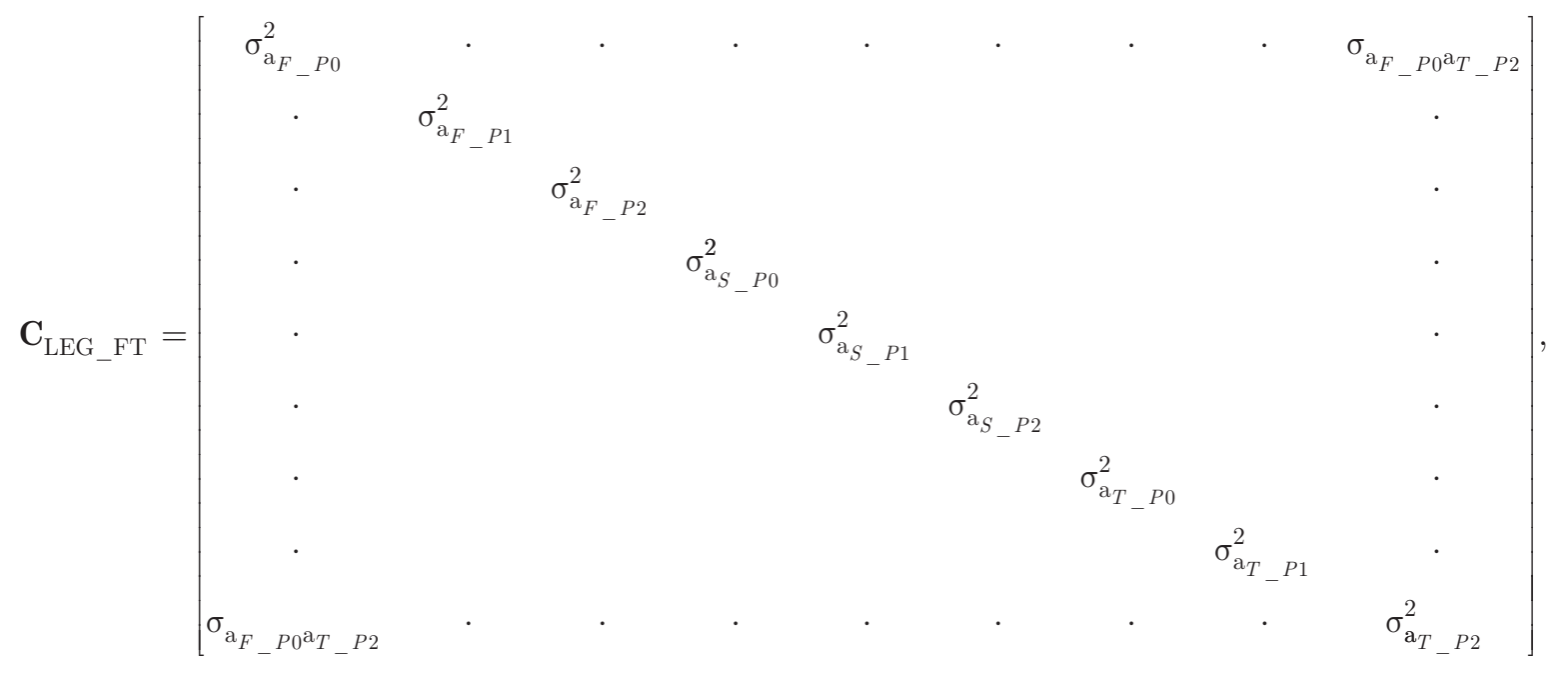

where $\sigma_{a_{x_{-} P o}}^{2}$ is the variance of the oth regression coefficient of Legendre polynomial $(3$ classes: $0,1,2)$ for the $x$ th parity [3 classes: first $(F)$, second $(S)$, third $(T)$ ], and $\sigma_{\mathrm{a}_{x_{-} P_{o}} \mathrm{a}_{x_{-} P_{o}}}$ is the covariance between the oth regression coefficient of Legendre polynomial of the $x$ th parity and the oth regression coefficient of Legendre polynomial of the $x$ th parity. The permanent environment variance-covariance matrix was defined in the same manner.

The EBV of goat $n$ for its 3 parities was obtained by summing the EBV for each DIM (3-lact-EBV).

RRM Using Eigenfunction. In a second step, the first 2 eigenvectors for each parity of the genetic variancecovariance matrix from LEG_FT, which can be associated with level of production and persistency, were multiplied by the Legendre polynomial coefficients to obtain eigenfunctions as shown in Druet et al. (2005). This makes it possible to obtain a reduced model that requires less computation capacity because fewer parameters have to be estimated $(2 \times 3$ instead of $3 \times 3)$. It also allows the information to be summarized in terms of level and persistence as shown in Arnal et al. (2019). These eigenfunctions were used for the genetic and the permanent environment parts of the model. The second eigenfunction was set to be negative at the beginning of the lactation, then positive as in Arnal et al. (2019) to model persistency. The reduced model (EGV_FT) was

$$
\begin{aligned}
& y_{t r s i j k l m d g n}=H T D_{t r i}+A_{t j k}+M_{t r j l}+D_{t r j m}+\sum_{o=1}^{6} \theta_{t k o} N_{(o, d)} \\
& +\sum_{o=1}^{6} \tau_{t r l o} N_{(o, d)}+\sum_{o=1}^{6} \pi_{t r m o} N_{(o, d)}+\sum_{o=1}^{4} \gamma_{t s o} M_{(o, g)}+\sum_{o=1}^{2} b_{t r n o} \chi_{(o r, d)} \\
& +\sum_{o=1}^{2} c_{t r n o} \chi_{(o r, d)}+e_{t r s i j k l m d g n},
\end{aligned}
$$

where $b_{\text {trno }}$ and $c_{\text {trno }}$ are the random additive genetic and permanent environmental regression coefficients for the oth eigenfunctions, and $\chi_{(o r, d)}$ is the value of the oth eigenfunction at DIM $d$ for parity $r$. The other effects were the same as in LEG_FT. The random additive genetic regression coefficient for the first eigenfunction, $b_{1}$, is noted LEV (related to production level) and for the second eigenfunction, $b_{2}$ is noted PERS (persistency). The 
3-lactation LEV EBV (3-lact-LEV-EBV) of goat $n$ was obtained by summing the LEV EBV of each parity. The 3-lactation PERS EBV (3-lact-PERS-EBV) of goat $n$ was obtained by summing the PERS EBV of each parity.

The genetic variance-covariance matrix $(\mathrm{C})$ for EGV_FT was

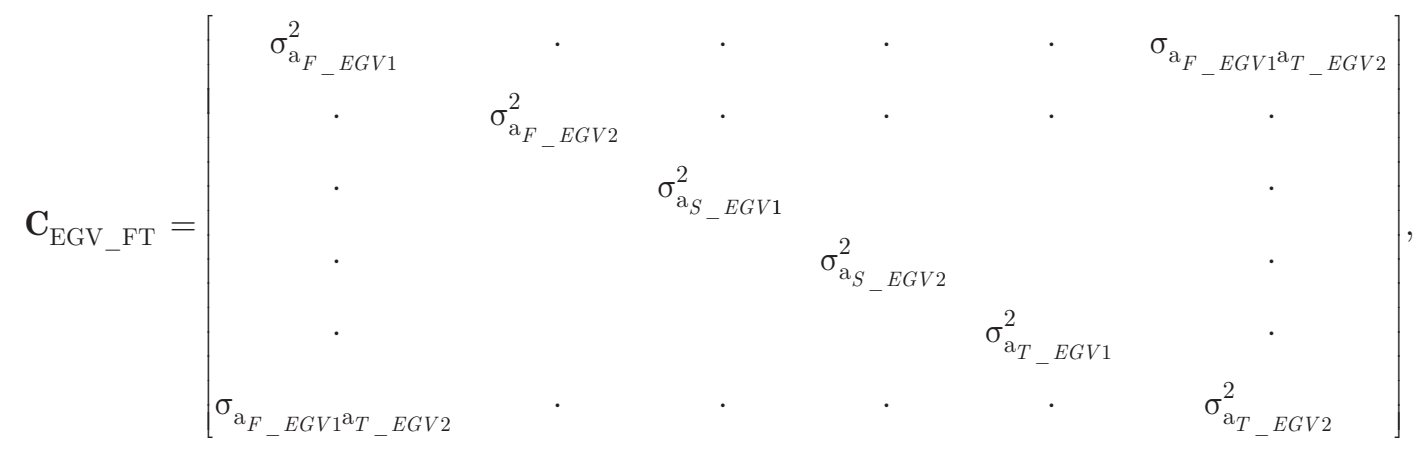

where $\sigma_{\mathrm{a}_{x_{-} E G V o}}^{2}$ is the variance of the oth regression coefficient of the eigenfunctions [2 classes: 1 (level of production throughout the lactation), 2 (persistency)] for the $x$ th parity [3 classes: first $(F)$, second $(S)$, third $(T)$ ], and $\sigma_{a_{x_{-} E G V o} \mathrm{a}_{x_{-} E G V o}}$ is the covariance between the oth regression coefficient of eigenfunctions of the $x$ th parity and the oth regression coefficient of eigenfunctions of the $x$ th parity. The permanent environment variance-covariance matrix was defined in the same manner.

\section{Primiparous and Multiparous}

To further simplify the model, the second and third parities (multiparous) were modeled together for genetic and permanent environment effects. For the fixed effects and the residual variance, the second and third parities were kept separate. The genetic and permanent environment effects were first modeled using a Legendre polynomial of degree 2 for primiparous and multiparous (model LEG_PM). The first 2 eigenvectors of the genetic variance-covariance matrix for primiparous and multiparous from LEG_PM were then multiplied by the terms of the Legendre polynomial to obtain eigenfunctions as above. These eigenfunctions were used for primiparous and multiparous for the genetic and the permanent environment parts of the model in (EGV_PM). As above, the second eigenfunction was set to be negative at the beginning of the lactation to model persistency. The random additive genetic regression coefficients for these 2 eigenfunctions are $b_{1}$, noted LEV (production level), and $b_{2}$, noted PERS (persistency).

The genetic variance-covariance matrix (C) for LEG_PM was defined as

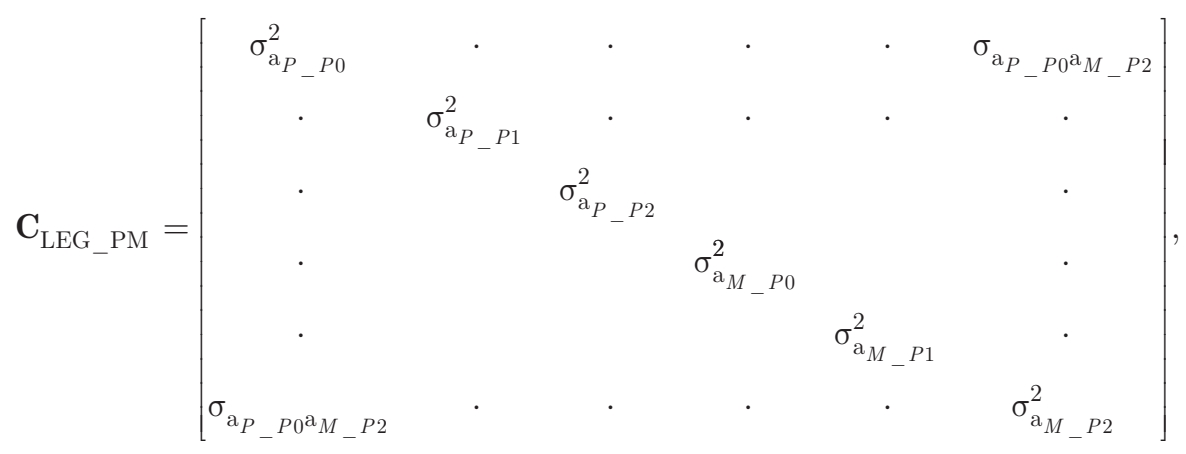

where $\sigma_{\mathrm{a}_{x_{-}} P_{0}}^{2}$ is the variance of the oth regression coefficient of Legendre polynomial $(3$ classes: $0,1,2)$ for the $x$ th parity [2 classes: primiparous $(P)$, multiparous $(M)]$, and $\sigma_{\mathrm{a}_{x_{-}} P \mathrm{a}_{x_{-}} P o}$ is the covariance between the oth regression coefficient of Legendre polynomial of the $x$ th parity and the oth regression coefficient of Legendre polynomial of the $x$ th parity. The permanent environment variance-covariance matrix was defined in the same manner. 
The genetic variance-covariance matrix (C) for EGV_PM was

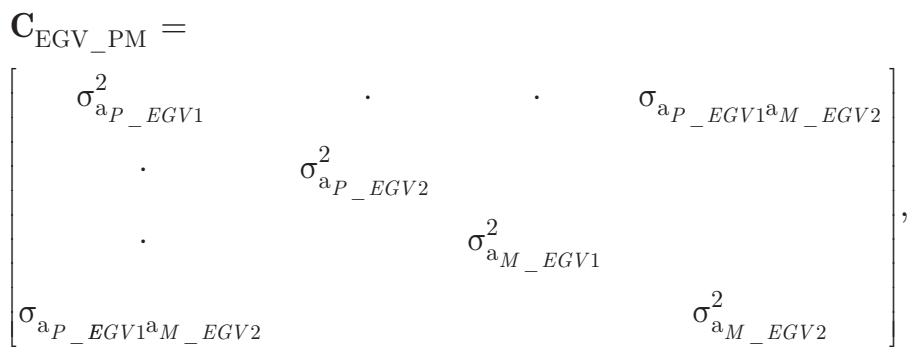

with $\sigma_{\mathrm{a}_{x} E G V o}^{2}$ the variance of the oth regression coefficient of the eigenfunctions [2 classes: 1 (level of production throughout the lactation), 2 (persistency)] for the $x$ th parity [2 classes: primiparous $(P)$, multiparous $(M)$ ], and $\sigma_{\mathrm{a}_{x_{-} E G V o} \mathrm{a}_{x_{-} E G V o}}$ is the covariance between the oth regression coefficient of eigenfunctions of the $x$ th parity and the oth regression coefficient of eigenfunctions of the $x$ th parity. The permanent environment variance-covariance matrix was defined in the same manner.

The EBV of goat $n$ for its 3 parities (3-lact-EBV) was obtained as for LEG_FT and EGV_FT. The 3-lact-LEVEBV of goat $n$ was obtained by multiplying the LEV EBV for primiparous by 0.33 and for multiparous by 0.66 . The same calculation was carried out for persistency to obtain 3-lact-PERS-EBV.

\section{Genetic Correlations and Heritability}

The genetic variance-covariance matrix among all DIM was derived following Druet et al. (2003) as $\mathbf{G}_{792}=\mathbf{Q C Q}$, where $\mathbf{G}$ is a $792(264$ DIM $\times 3$ parities $=$ 792 DIM) by 792 genetic (co)variance matrix, $\mathbf{C}$ is the $(o \times x)$ by $(o \times x)$ variance covariance matrix, and $\mathbf{Q}$ is a 792 by an $(o \times x)$ matrix with the values of the $o$ terms of Legendre polynomial repeated for each parity for LEG models or the $o$ eigenfunctions for each parity for EGV models and $x$ is the number of parities.

The same approach was used to obtain the permanent environmental variance-covariance matrix $\mathbf{W}_{792}$. The phenotypic variance-covariance matrix between all DIM, $\mathbf{P}_{792}$, was obtained by summing $\mathbf{G}_{792}, \mathbf{W}_{792}$, and the residual variance for the relevant DIM. The daily heritabilities were obtained by dividing the diagonal elements of $\mathbf{G}_{x}$ by the diagonal elements of $\mathbf{P}_{x}$.

The genetic correlation between the $d$ th DIM and the other DIM is the $d$ th column of $\mathbf{G}_{792}$.

The heritability of the oth regression coefficients were calculated by dividing the genetic variance of the oth regression coefficient by the sum of the genetic variance of the oth regression coefficient, the permanent environment variance of the oth regression coefficient and the mean square error as in Schaeffer (2016). This calculation was used to calculate the heritabilities of LEV and PERS.

All the genetic parameters were estimated using the WOMBAT software (Meyer, 2007).

\section{Model Selection Criteria}

The Pearson correlations between the EBV of bucks obtained from the different models were studied to compare and assess the closeness of the models.

\section{RESULTS}

The genetic correlations between the second and third parity regression coefficients with the LEG_FT and EGV_FT models are shown in Table 2. Genetic correlations were very high (values between 0.92 and 1) for both models and all traits, except for SCS, where genetic correlations were equal to $0.73,0.80$, and 0.83 for PERS, and $a_{2}$ and $a_{1}$ Legendre coefficients, respectively. These results prompted us to combine the second and third lactations into a single category (i.e., multiparous), when modeling the genetic and the permanent environment components of each trait. This was done through the LEG_PM model, which used a Legendre polynomial of order 2 for the genetic and permanent environment components for each parity, and the EGV_PM model, which used the first 2 eigenvectors of the LEG_PM variance-covariance matrix for each parity.

\section{Model Fitting}

The different models were compared based on their estimated residual variances for milk yield according to 
Table 2. Genetic correlation estimates of the 3 terms of the Legendre polynomial coefficients $\left(a_{0}, a_{1}, a_{2}\right.$ in LEG_FT) and of the regression coefficients of the first 2 eigenfunctions (LEV, PERS in EGV_FT) in second and third lactations in Alpine goats ${ }^{1}$

\begin{tabular}{lcccccc}
\hline Item & Milk yield & Fat yield & Protein yield & Fat content & Protein content & SCS \\
\hline$a_{0}$ & 0.95 & 0.95 & 0.95 & 1.00 & 1.00 & 0.99 \\
$a_{1}$ & 0.95 & 0.95 & 0.95 & 0.97 & 0.99 & 0.83 \\
$a_{2}$ & 0.94 & 0.92 & 0.93 & 0.97 & 0.97 & 0.80 \\
LEV & 0.95 & 0.95 & 0.94 & 1 & 0.99 & 0.96 \\
PERS & 0.96 & 0.92 & 0.95 & 0.99 & 0.98 & 0.99 \\
\hline
\end{tabular}

${ }^{1}$ LEG_FT = Legendre polynomial of order 2 for each parity to describe the genetic and permanent environment effects; LEV $=$ random additive genetic regression coefficient for the first eigenfunction; PERS = random additive genetic regression coefficient for the second eigenfunction; EGV_FT = eigenfunctions used for each parity to describe the genetic and permanent environment effects; FPR $=$ fat-protein ratio.

DIM in Figure 1. The residual variance was smallest with LEG_FT for all DIM, parities, and traits. For the first lactation, residual variance according to days for LEG_PM and LEG_FT were totally superposed. And similarly the evolution of residual variance for EGV PM and EGV_FT were also totally superposed in first lactation (Figure 1). When the multiparous lactations were modeled together, the residuals were higher, especially for the third lactation. Residual variance estimates with the LEG_FT model were very close to those with the EGV_FT and to those of the LEG_PM and EGV_PM models, except at the beginning and end of lactation, where estimates with LEG models were smaller (i.e., better) than with EGV models. Changing the Legendre polynomials by eigenfunctions (LEG_FT to EGV_FT or LEG_PM to EGV_PM) generate less residuals than putting together multiparous parities (LEG_FT to LEG_PM or EGV_FT to EGV_PM). The higher residual variances were due to permanent environment effects not being well modeled with EGV FT and combining 2 and 3 parities (results not shown).

\section{Estimated Genetic Variance}

The evolution of estimated TD genetic variances according to DIM for milk yield is presented in Figure 2. The variances increased from the first to the third parity following the same pattern (a bell curve). The evolution of genetic variance in first lactation for LEG_PM and LEG_FT were totally superposed. And similarly genetic variances according to DIM for EGV_PM and EGV_FT were also totally superposed in first lactation. Smaller differences were found between FT models and between PM models compared with residual variances. For yield traits, the genetic variances were higher in third than in second parity. To combine the second and the third parities together, we multiplied, for the third parity, the Legendre covariables for LEG_PM and the eigenfunction for EGV_PM by 1.1 for MY, and by 1.2 for FY and PY. These coefficients were chosen to have the best third lactation genetic variance (results not shown). When the second and third parities were combined, the genetic variance for yield traits and SCS with PM models was higher than with FT models in the second parity, but smaller in the third parity. However, for contents, the phenotypic means and the genetic variances were similar between parities (results not shown).

\section{Heritabilities}

The evolution of TD heritabilities for the different traits is shown in Figure 3. Few variations were found between parities. The highest heritabilities were found for protein content (around 0.6), then fat content (around 0.45), FPR (around 0.35), yield traits (around 0.25 ), and SCS (around 0.15). Table 3 compares the heritabilities for the regression coefficients of EGV_FT and EGV_PM. Again, few differences were observed between the 2 models (FT and PM). The heritabilities of LEV were quite similar between parities and equal to the mean of the TD heritabilities shown in Figure 3. The heritabilities of PERS ranged between 0.04 (for SCS) and 0.21 (for protein content) in the first parity. Heritabilities of PERS for the second and third parities for yield traits were higher than those found in the first parity (e.g., 0.10 for milk yield in the first parity and 0.17 for multiparous); this was not the case for contents, FPR, and SCS, for which heritabilities were equal to those found in the first lactation.

\section{Estimated Genetic Correlations}

The genetic correlations between DIM 40 (close to the lactation peak) in the second parity and all other DIM for milk yield were compared according to the models used in Figure 4. Few differences were observed between models. Correlations decreased to about +0.5 in the second parity. As seen in Table 2, the evolution of the genetic correlations between DIM 40 in the second lactation and all DIM in the third lactation was similar to the evolution in the second parity. Combining second and third lactations in the LEG_PM and EGV_PM models is thus sound, giving a genetic correlation es- 
timated of 1 between DIM 40 in the 2 lactations compared with 0.98. By contrast, the correlation between DIM 40 in first and second lactations was only 0.85 , confirming that yield traits in first and later lactations are genetically different. However, the genetic correlation curve shapes were the same between parities.

The same correlations between DIM 40 in the second lactation and all DIM from LEG_FT for all the traits are plotted in Figure 5. The highest correlations be- tween the beginning and end of lactation in the second parity were observed for SCS (higher than 0.85), then contents (around 0.80), FPR (around 0.70), and finally yield traits. The correlations between DIM 40 in the second and third parities were always close to 1 , and the shapes of the correlations for the different traits were again very similar, as seen in Table 2. Smaller correlations between DIM 40 in the second parity and end of lactation were observed for yields in the third compared

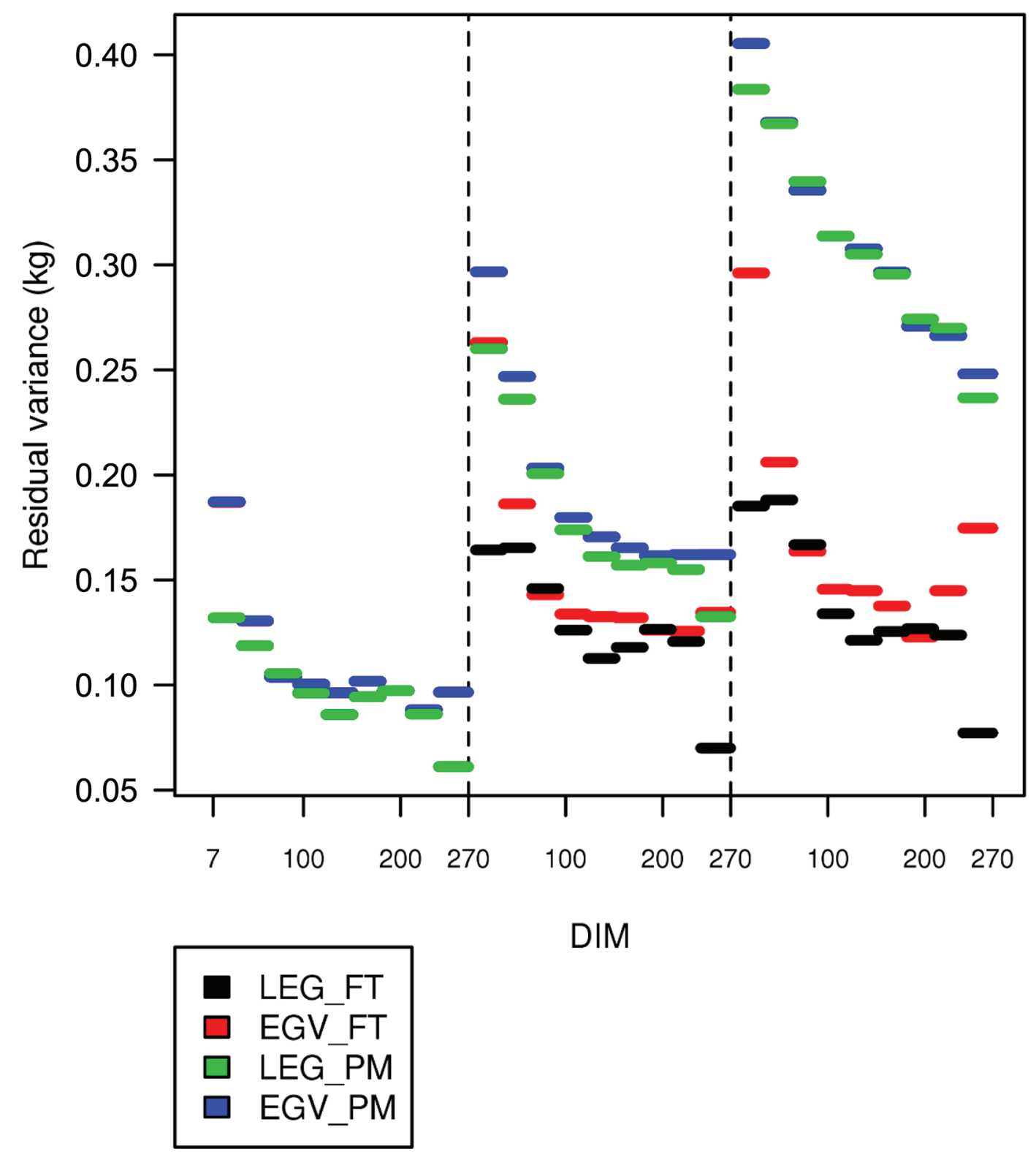

Figure 1. Evolution of the estimated residual variance according to DIM for the different models for milk yield in Alpine goats. Evolution for LEG_PM and LEG_FT was totally superposed in first lactation. EGV_PM and EGV_FT were also totally superposed in first lactation. LEG_FT = Legendre polynomial used for the modeling of genetic and permanent environment from first to third parity; LEG_PM $=$ Legendre polynomial used for the modeling of genetic and permanent environment for primiparous and multiparous; EGV_FT = eigenfunctions used for the modeling of genetic and permanent environment from first to third parity; EGV_PM = eigenfunctions used for the modeling of genetic and permanent environment for primiparous and multiparous. 
with the second parity. However, clear trait differences were observed between DIM 40 in the first and second lactations: correlations were much higher for contents (0.95) than FPR (0.92), yields (0.85), and SCS $(<0.75)$. For all traits and parities, the within-parity correlations decreased with distance from DIM 40, except for SCS in the first parity. Correlations between DIM 40 in the second parity and DIM of the first lactation for SCS were higher in mid-lactation (between DIM 150 and DIM 200).

\section{EBV Correlations Between Models}

The Pearson correlations between the 3-lact-EBV from the LEG models, 3-lact-LEV-EBV, and 3-lactPERS-EBV from EGV models for AI bucks, sires of the

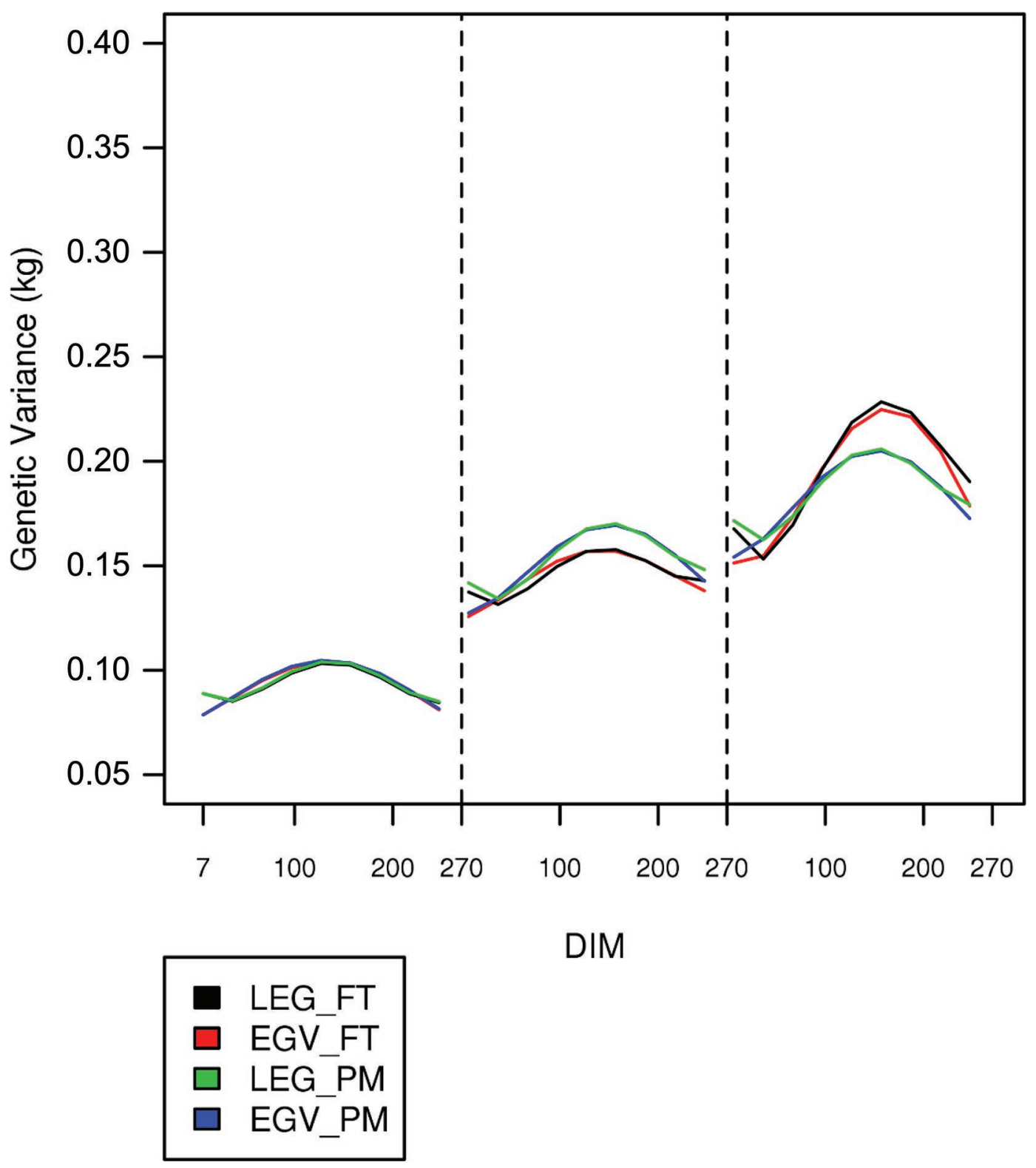

Figure 2. Test-day genetic variances for 4 models for milk yield in Alpine goats. Curves of LEG_PM and LEG_FT were totally superposed in first lactation. Curves of EGV_PM and EGV_FT were also totally superposed in first lactation. LEG_FT = Legendre polynomial of order 2 for each parity to describe the genetic and permanent environment effects; LEG_PM = Legendre polynomial of order 2 for primiparous and multiparous to describe the genetic and permanent environment effects; EGV_FT = eigenfunctions used for each parity to describe the genetic and permanent environment effects; EGV_PM = eigenfunctions used for primiparous and multiparous to describe the genetic and permanent environment effects. 
recorded goats $(\mathrm{n}=486)$, were calculated to evaluate the closeness of the models in Table 4 for milk yield. Sires of the recorded goats were all from an AI center, with at least 20 daughters in the data set. The EBV of these animals were considered reliable given daughter number. The correlations between the 3-lact-EBV derived from the 2 LEG models (LEG-FT and LEG-PM), between the 3-lact-LEV-EBV and between the 3-lactPERS-EBV of the 2 EGV models were all greater than or equal to 0.99 , confirming that modeling second and third parities together generated little differences. The correlations between the 3-lact-LEV-EBV from EGV and the 3-lact-EBV from LEG were also equal to 1 , showing that the reduced model using the 2 main eigenvalues fitted well, and that its LEV component truly represented the level of production throughout the lactations. The correlations between 3-lact-LEVEBV and 3-lact-PERS-EBV were close to $0(-0.04$ for EGV_FT and -0.02 for the EGV_PM) showing that the reduced model uncorrelated level of production and

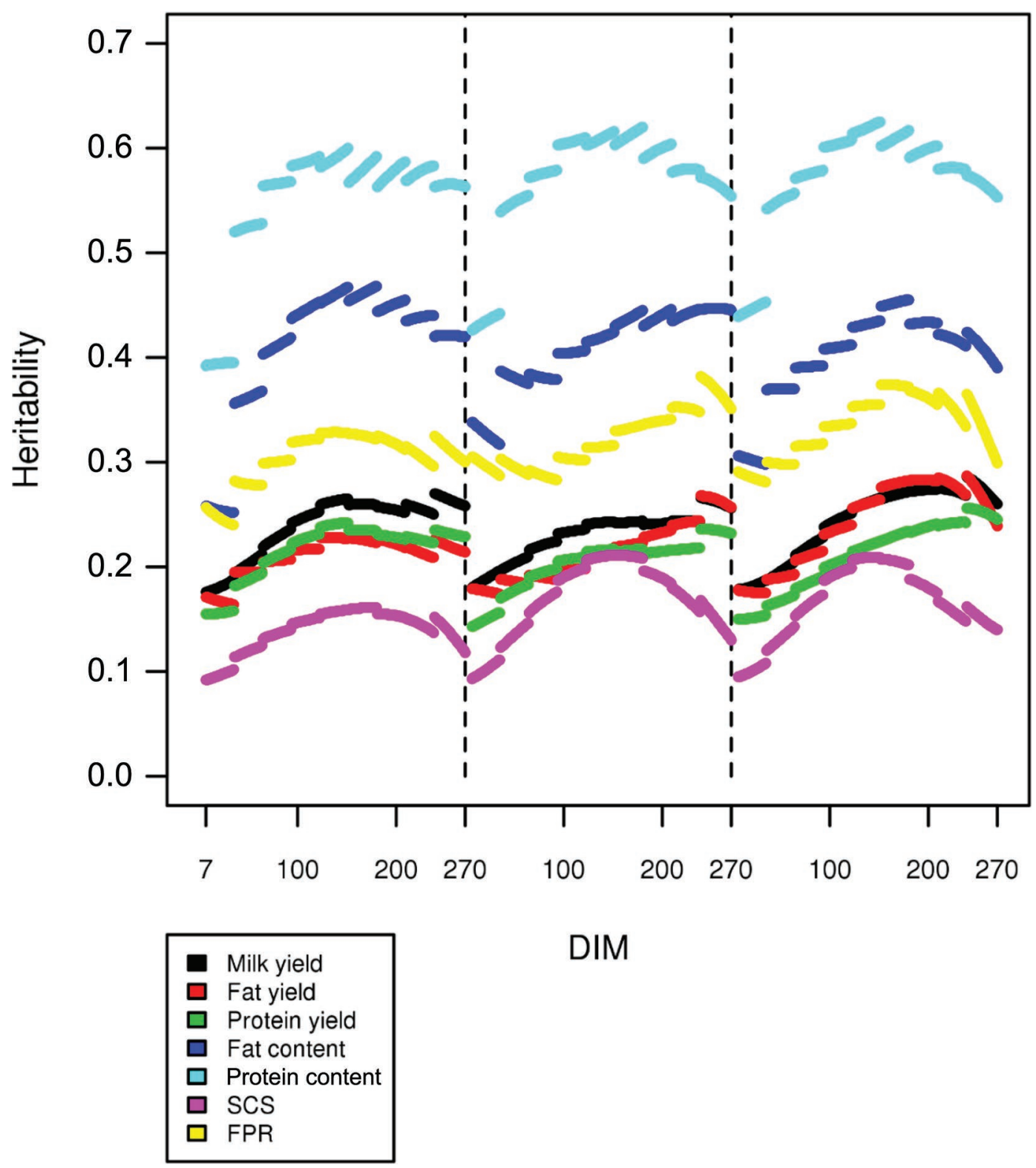

Figure 3. Test-day heritabilities for the different traits with the LEG_FT model in Alpine goats. LEG_FT = Legendre polynomial used for the modeling of genetic and permanent environment from first to third parity; FPR = fat/protein ratio. 
Table 3. Heritability of each component from EGV_FT and EGV_PM for each trait in Alpine goats ${ }^{1}$

\begin{tabular}{|c|c|c|c|c|c|c|c|c|c|}
\hline Model & Parity & & Milk yield & Fat yield & Protein yield & Fat content & Protein content & SCS & FPR \\
\hline EGV_PM & Primiparous & $\mathrm{LEV}_{\mathrm{P}}$ & 0.26 & 0.23 & 0.24 & 0.55 & 0.65 & 0.19 & 0.42 \\
\hline EGV_FT & First & $\mathrm{PERS}_{\mathrm{F}}$ & 0.12 & 0.09 & 0.09 & 0.1 & 0.21 & 0.05 & 0.1 \\
\hline EGV_FT & Second & $\mathrm{LEV}_{\mathrm{S}}$ & 0.27 & 0.26 & 0.24 & 0.55 & 0.66 & 0.22 & 0.45 \\
\hline EGV_FT & Third & $\mathrm{LEV}_{\mathrm{T}}$ & 0.28 & 0.29 & 0.24 & 0.53 & 0.65 & 0.21 & 0.46 \\
\hline EGV_PM & Multiparous & $\mathrm{LEV}_{\mathrm{M}}$ & 0.28 & 0.27 & 0.25 & 0.54 & 0.67 & 0.23 & 0.46 \\
\hline EGV_PM & Multiparous & PERS $_{M}$ & 0.17 & 0.14 & 0.14 & 0.1 & 0.19 & 0.02 & 0.11 \\
\hline
\end{tabular}

${ }^{1}$ EGV_FT = eigenfunctions used for each parity to describe the genetic and permanent environment effects; EGV_PM = eigenfunctions used for primiparous and multiparous to describe the genetic and permanent environment effects; LEV = random additive genetic regression coefficient for the first eigenfunction; PERS = random additive genetic regression coefficient for the second eigenfunction; FPR $=$ fat $/$ protein ratio.

persistency. Similar results were obtained for the other traits (results not shown).

\section{EBV Correlations Between Traits}

For residual variances, genetic variances, genetic correlations between DIM, and EBV correlations, the 4 models gave similar results. The EGV_PM, which took the shortest computational time (EGV_FT was 1.15 times longer, LEG_PM 1.43 times longer, and LEG_FT 2.25 times longer for milk yield) and whose interpretation was easy, was chosen.

The correlations between milk yield EBV of Alpine AI bucks and yields, contents, and SCS EBV from the EGV_PM model are presented in Table 5. High positive correlations were observed between 3-lact-LEVEBV of milk yield and 3-lact-LEV-EBV of other yield traits ( 0.73 for fat yield and 0.88 for protein yield). Negative correlations were found between 3-lact-LEVEBV of milk yield and 3-lact-LEV-EBV of contents ( -0.3 with fat content, -0.46 with protein content). Correlations were nil between milk 3-lact-LEV_EBV and FPR 3-lact-LEV-EBV and slightly negative with SCS 3-lact-LEV-EBV (-0.14). Correlation between 3-lact-LEV-EBV of milk yield and 3-lact-PERS-EBV of other traits were close to 0 (minimum: 0 for protein yield, maximum: -0.19 for SCS) together with the correlations between 3-lact-PERS-EBV of milk yield and for the other trait 3-lact-LEV-EBV. The correlation between 3-lact-PERS-EBV of milk yield and fat content 3-lact-PERS-EBV was close to 0 and moderately negative with SCS 3-lact-PERS-EBV $(-0.24)$, whereas this correlation was strongly negative with protein content 3-lact-PERS-EBV (-0.64). Consequently, the correlation between 3-lact-PERS-EBV of milk yield and FPR 3-lact-PERS-EBV was positive (0.43). As for production level, the correlations between persistencies of yield traits were very high (0.89 for fat yield and 0.94 for protein yield). The same correlations between traits were obtained when studying only measured goat EBV.

\section{DISCUSSION}

The results presented pertain the Alpine breed (almost $60 \%$ of goats in France). The same analyses were performed in French Saanen goats and similar results were obtained for all traits (results not shown). The estimation of genetic parameters was based on a large number of goats measured regularly throughout their lactation. The connectedness between the large number of herds was ensured by the use of phenotypes of daughters of AI bucks.

The LEG_FT was considered as the reference (full) model. Genetic and permanent environment effects were modeled with a Legendre polynomial of order 2 as proposed by Arnal et al. (2019), which studied first lactation traits in dairy goats in France. They showed that a Legendre polynomial of order 2 was close to a more complex Legendre polynomial of order 4 in goodness-of-fit and genetic parameters. A model using a Legendre polynomial of order 4 , for each parity, would thus provide little additional precision and be too time consuming in routine use for genetic evaluation on a complete data set.

The EGV_FT was compared with LEG_FT. The EGV_FT model was the extension of the reduced model proposed by Arnal et al. (2019), which was satisfactory in terms of goodness-of-fit and genetic parameters, summarizing the relevant information for production level (LEV) and persistency (PERS).

Goodness-of-fit was better at the beginning and end of lactation with a complete model than with a reduced model using eigenfunctions, as shown by Arnal et al. (2019) with data on first parity goats only. However, the genetic variances and between-DIM genetic correlations were very similar between complete models 
and reduced models using eigenfunctions. The reduced models therefore represent attractive alternatives to the complete analysis for routine genetic evaluations.

We showed that EBV correlations for production level were close to 1 between LEG_FT, EGV_FT, LEG_PM, and EGV_PM, in good agreement with Leclerc et al. (2009) and Arnal et al. (2019), who compared EBV from a complete and a reduced model. The advantages of the reduced model are first the smaller size of the variance-covariance matrices, a shorter computing time, and also the zero correlation between the EBV for production level and persistency by construc- tion. This enables us to select animals with a desired persistency throughout lactation without changing the total lactation production.

Modeling the second and third parities together led to larger residuals, especially for the third parity. A way to avoid this increase could be to not model together parities 2 and 3 for the permanent environment effect but only for genetic part. This was not implemented in order the more reduced models could be fitted. For the genetic variances, some differences were also found between models considering all parities separately or those combining the second and third. However, re-

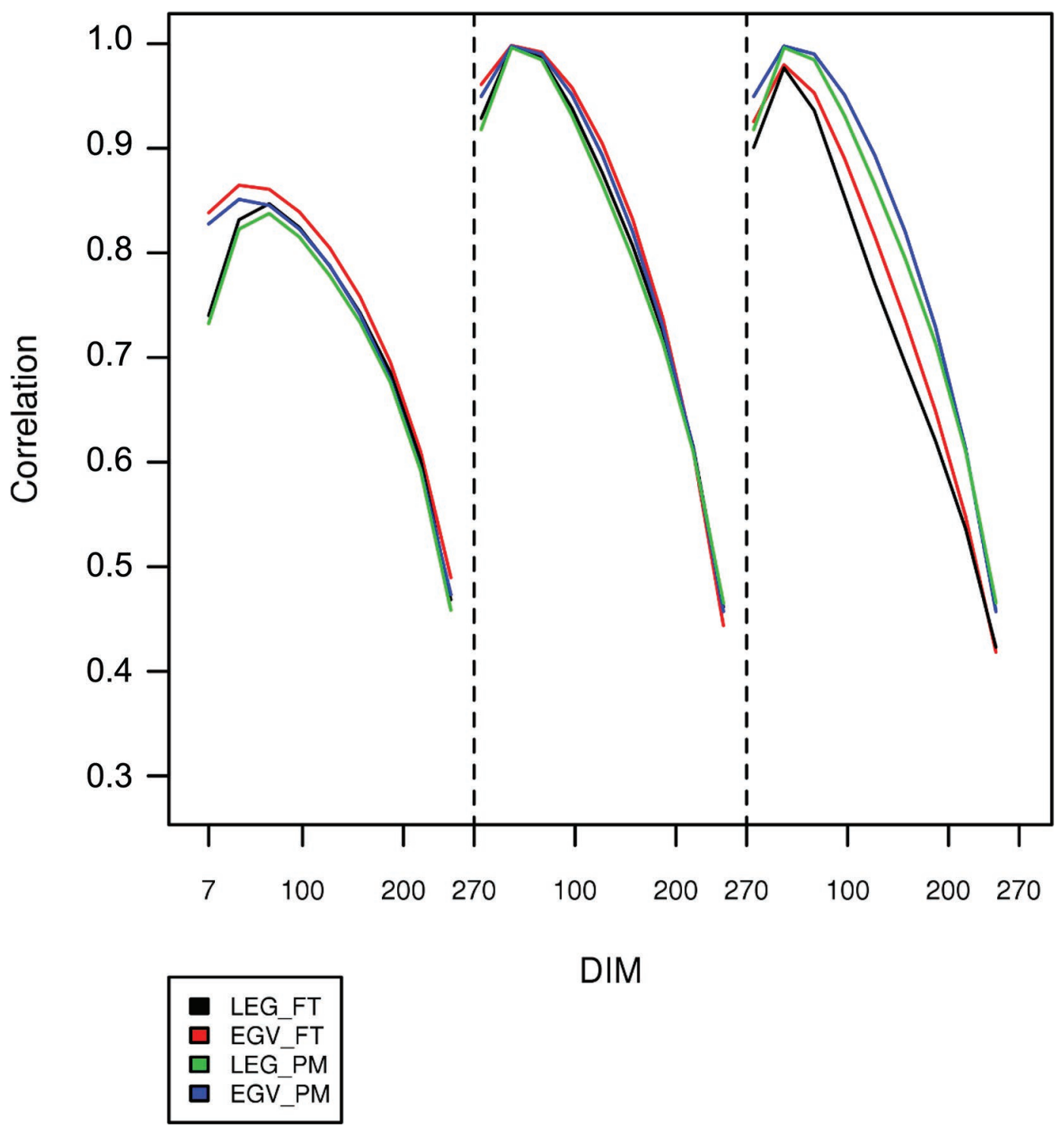

Figure 4. Genetic correlations between DIM 40 in second parity and the other DIM with the different models for milk yield in Alpine goats. LEG_FT = Legendre polynomial of order 2 for each parity to describe the genetic and permanent environment effects; LEG_PM = Legendre polynomial of order 2 for primiparous and multiparous to describe the genetic and permanent environment effects; EGV_FT = eigenfunctions used for each parity to describe the genetic and permanent environment effects; EGV_PM = eigenfunctions used for primiparous and multiparous to describe the genetic and permanent environment effects. 
garding the heritabilities and the buck EBV (production throughout 3 parities and persistency) when the reduced model was applied, few differences were found from the models considering all parities separately. The model combining second and third lactations and using eigenfunctions was therefore preferred for routine calculations because of its shorter computing time and its ease of interpretation.

The heritabilities estimated for production level and persistency for primiparous goats confirmed those reported by Arnal et al. (2019), with partly the same animals and also a reduced model. The production level heritabilities were in line with Rupp et al. (2011), who found a heritability of 0.2 for SCS in primiparous Alpine goats in France with a lactation model, and similar heritabilities for yields and contents. We found heritabilities for total milk production yield similar to other studies on different breeds of goats using RRM (Zumbach et al., 2008; Menéndez-Buxadera et al., 2010; Mucha et al., 2014). For yield traits, we also found heritabilities similar to Menéndez-Buxadera et al. (2010). Using an RRM, Apodaca-Sarabia et al. (2009) found, like us, a heritability between 0.12 and 0.25 for SCS in a goat population of New Zealand, mixing parities.

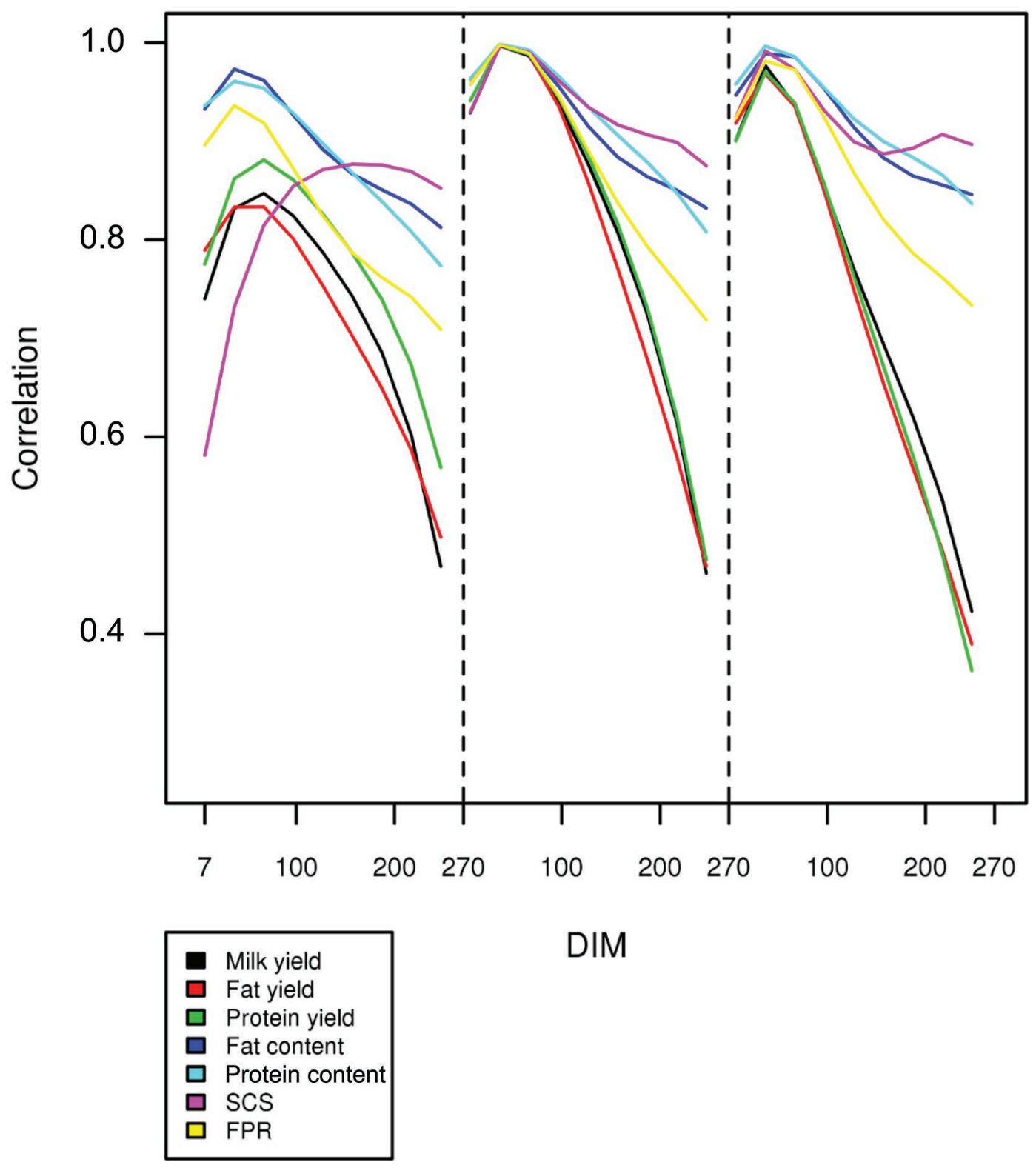

Figure 5. Genetic correlations with model LEG_FT between DIM 40 in second lactation and all DIM for all traits in Alpine goats. LEG_FT $=$ Legendre polynomial of order 2 for each parity to describe the genetic and permanent environment effects; FPR = fat/protein ratio. 
Table 4. Estimated breeding value correlations of bucks $(n=486)$ according to the model for milk yield in Alpine goats ${ }^{1}$

\begin{tabular}{|c|c|c|c|c|c|c|}
\hline & & LEG_FT & LEG_PM & EGV_FT & EGV_PM & EGV_FT \\
\hline EGV_PM & 3-lact-LEV-EBV & 1 & 1 & 1 & & \\
\hline EGV_FT & 3-lact-PERS-EBV & -0.06 & -0.07 & -0.04 & -0.06 & \\
\hline EGV_PM & 3-lact-PERS-EBV & -0.01 & -0.02 & 0 & -0.02 & 0.99 \\
\hline
\end{tabular}

${ }^{1}$ LEG_FT $=$ Legendre polynomial of order 2 for each parity to describe the genetic and permanent environment effects; LEG_PM $=$ Legendre polynomial of order 2 for primiparous and multiparous to describe the genetic and permanent environment effects; EGV_FT = eigenfunctions used for each parity to describe the genetic and permanent environment effects; EGV_PM = eigenfunctions used for primiparous and multiparous to describe the genetic and permanent environment effects; 3-lact-EBV = sum of the EBV for each DIM throughout all parities; 3-lact-LEV-EBV = sum of the random additive genetic regression coefficient for the first eigenfunction throughout all parities (for LEG_PM and EGV_PM, the random additive genetic regression coefficient for the first eigenfunction in primiparous was multiplied by 0.33 and the one of multiparous by 0.66); 3-lact-PERS-EBV = sum of the random additive genetic regression coefficients for the second eigenfunction throughout all parities (for LEG_PM and EGV_PM, the random additive genetic regression coefficient for the second eigenfunction in primiparous was multiplied by 0.33 and that of multiparous by 0.66$)$.

We found a heritability close to 0.3 for FPR for the first 3 parities, in good agreement with Nishiura et al. (2015) who studied FPR in Holstein dairy cows, using an RRM.

We report a heritability of 0.1 for 3-lactation milk yield persistency, but Menéndez-Buxadera et al. (2010) reported a higher heritability $(0.20)$ considering the second eigenfunction of their variance-covariance matrix. These heritabilities are of the same order, and the small difference may be due to breed differences. In dairy cows, Haile-Mariam et al. (2003) found, like us, that fat persistency heritability (0.06) was smaller than milk yield persistency. Cole and VanRaden (2006) reported a milk yield persistency heritability similar to ours in dairy cows, mixing parities, with no correlation with milk yield. Like us, they found smaller heritabilities for fat yield persistency (0.07), protein yield persistency (0.09), and especially SCS persistency (0.03) than for milk yield persistency.

In line with our study, the other RRM goat studies (Zumbach et al., 2008; Menéndez-Buxadera et al., 2010; Mucha et al., 2014) reported similar genetic correlations between DIM and between parities for milk yield. For other yield traits, Menéndez-Buxadera et al. (2010) reported correlations similar to ours. For SCS in dairy cows, Zavadilová et al. (2011) investigated the genetic

Table 5. Estimated breeding value correlations of Alpine bucks $(\mathrm{n}=486)$ from EGV_PM between milk yield and other traits [fat yield, protein yield, fat content, protein content, SCS, and fat/protein ratio (FPR) $]^{1}$

\begin{tabular}{llcr}
\hline & & \multicolumn{2}{c}{ Milk yield } \\
\cline { 3 - 4 } Item & & 3-lact-LEV-EBV & 3-lact-PERS-EBV \\
\hline Fat yield & 3-lact-LEV-EBV & 0.73 & -0.06 \\
Protein yield & 3-lact-PERS-EBV & 0.13 & 0.89 \\
& 3-lact-LEV-EBV & 0.88 & -0.02 \\
Fat content & 3-lact-PERS-EBV & 0.94 \\
& 3-lact-LEV-EBV & -0.3 & 0.03 \\
Protein content & 3-lact-PERS-EBV & -0.05 & -0.01 \\
\multirow{2}{*}{ SCS } & 3-lact-LEV-EBV & -0.04 & -0.07 \\
& 3-lact-PERS-EBV & -0.14 & -0.64 \\
FPR & 3-lact-LEV-EBV & -0.19 & -0.16 \\
& 3-lact-PERS-EBV & 0.01 & -0.24 \\
& 3-lact-LEV-EBV & 0.02 & 0.05 \\
& 3-lact-PERS-EBV & & 0.43 \\
\hline
\end{tabular}

${ }^{1} \mathrm{EGV} \_\mathrm{PM}=$ eigenfunctions used for primiparous and multiparous to describe the genetic and permanent environment effects; 3-lact-LEV-EBV = sum of the random additive genetic regression coefficient for the first eigenfunction throughout all parities (for LEG_PM and EGV_PM, the random additive genetic regression coefficient for the first eigenfunction in primiparous was multiplied by 0.33 and the one of multiparous by 0.66); LEG_PM = Legendre polynomial of order 2 for primiparous and multiparous to describe the genetic and permanent environment effects; 3-lact-PERS-EBV = sum of the random additive genetic regression coefficients for the second eigenfunction throughout all parities (for LEG_PM and EGV_PM, the random additive genetic regression coefficient for the second eigenfunction in primiparous was multiplied by 0.33 and that of multiparous by 0.66$)$. 
correlation between DIM 40 and all DIM of all parities with a random regression model, and reported, like us, that the highest correlation between DIM 40 in the second lactation and DIM in the first lactation was not at DIM 40 but at DIM 100. As in Druet et al. (2005) and Arnal et al. (2019), higher genetic correlations were found between the beginning and end of lactation for content traits than for yield traits.

The correlations between production level for milk yield and for the other traits were very close to those estimated in the first parity by Arnal et al. (2019) and by Bélichon et al. (1999) on total lactation traits (0.90 for protein yield and 0.76 for fat yield in Bélichon et al. (1999) and 0.88 and 0.73 for protein and fat yields, respectively, in our study). They were slightly weaker in Bélichon's analysis for contents: -0.28 for protein content, and -0.13 for fat content versus -0.46 and -0.3 , respectively, in the present study. In terms of selection, these negative correlations between contents and milk yield are a brake on increasing protein yield. Rupp et al. (2011) found a zero correlation between milk yield and SCS in the first parity, close to our result $(-0.14)$. In Holstein dairy cows, Cole and VanRaden (2006) found, like us, small correlations between milk production level and milk persistency and a negative one between milk yield level and SCS persistency $(-0.23)$. Cole and VanRaden (2006) reported correlations close to 1 between milk yield persistency and fat and protein yield persistencies, high correlation between fat and protein yield persistencies, as we did, and a negative correlation between milk persistency and SCS persistency as in our application $(-0.24)$. The correlation between milk yield persistency and LEV of contents was close to zero, so that milk yield persistency can be selected with no effect on contents. However, the negative high genetic correlation between protein content persistency and milk yield persistency indicated that a goat with a more persistent milk production will often have a higher protein content at the beginning of lactation than an average animal with the same protein content throughout lactation. Similar conclusions were drawn when the permanent environment of the animal was added to its EBV. Buttchereit et al. (2011) and Negussie et al. (2013), in dairy cows, reported that a decrease in FPR at the beginning of the lactation was genetically correlated with a decrease in milk yield. We confirmed this result in goats. Milk yield persistency (less milk at the beginning of lactation than a goat producing the same amount of milk throughout lactation) was positively correlated $(+0.43)$ with FPR persistency (i.e., smaller FPR at the beginning of the lactation), which could be used to select for better fitness, because metabolic diseases were found to be correlated with high FPR at the beginning of lactation (Buttchereit et al., 2011; Jamrozik and Schaeffer, 2012; Koeck et al., 2013; Negussie et al., 2013). A negative genetic correlation was found in dairy ewes (Riggio et al., 2009) and in dairy cows (Caraviello et al., 2005; Sewalem et al., 2006) between high SCS and longevity. The negative correlation between PERS milk yield and LEV SCS suggests that a more persistent goat could live longer. This emphasizes the potential benefit of selecting for lactation persistency in breeding programs. The correlation between milk yield persistency and fertility has to be studied to evaluate a potential antagonism between the two (Pryce et al., 2004; Dobson et al., 2007). In dairy cows, reproduction, in a scheme with a calving each year, occurs around DIM 90, so no antagonism between fertility and persistency was found (Harder et al., 2006; Albarrán-Portillo and Pollott, 2013). However, in dairy goats, the reproduction is at the end of lactation (around 210 DIM) in herds with a kidding each year, so an antagonism could arise.

\section{CONCLUSIONS}

We show that the genetic parameters and EBV obtained with a reduced rank TD model grouping together multiparous goats are similar to those derived from a complete model using a traditional Legendre polynomial for each parity. This reduced model yields production level and persistency EBV per lactation. These are nearly genetically independent, so that animals with a desired lactation shape can be selected independently of their total milk yield production. The positive genetic relationship between milk persistency and FPR persistency may offer a way to genetically offset negative energy balance at the beginning of lactation.

\section{ACKNOWLEDGMENTS}

The first author received financial support from APIS-GENE (Paris, France) and the French National Association for Research and Technology (ANRT, Paris, France). The authors thank Karin Meyer (University of New England, Armidale, Australia) for the WOMBAT program. The authors have not stated any conflicts of interest.

\section{REFERENCES}

Albarrán-Portillo, B., and G. E. Pollott. 2013. The relationship between fertility and lactation characteristics in Holstein cows on United Kingdom commercial dairy farms. J. Dairy Sci. 96:635646. https://doi.org/10.3168/jds.2012-5632.

Apodaca-Sarabia, C. A., N. Lopez-Villalobos, H. T. Blair, and G. G. Prosser. 2009. Genetic parameters for somatic cell score in dairy goats estimated by random regression. Pages 206-209 in Proceed- 
ings of the New Zealand Society of Animal Production. New Zealand Society of Animal Production, Christchurch, New Zealand.

Arnal, M., H. Larroque, H. Leclerc, V. Ducrocq, and C. RobertGranié. 2019. Genetic parameters for first lactation dairy traits in the Alpine and Saanen goat breeds using a random regression test-day model. Genet. Sel. Evol. 51:43. https://doi.org/10.1186/ s12711-019-0485-3.

Arnal, M., C. Robert-Granié, and H. Larroque. 2018. Diversity of dairy goat lactation curves in France. J. Dairy Sci. 101:11040-11051. https://doi.org/10.3168/jds.2018-14980.

Bélichon, S., E. Manfredi, and A. Piacère. 1999. Genetic parameters of dairy traits in the Alpine and Saanen goat breeds. Genet. Sel. Evol. 31:529-534. https://doi.org/10.1186/1297-9686-31-5-529.

Buttchereit, N., E. Stamer, W. Junge, and G. Thaller. 2011. Genetic relationships among daily energy balance, feed intake, body condition score, and fat to protein ratio of milk in dairy cows. J. Dairy Sci. 94:1586-1591. https://doi.org/10.3168/jds.2010-3396.

Caraviello, D. Z., K. A. Weigel, G. E. Shook, and P. L. Ruegg. 2005. Assessment of the impact of somatic cell count on functional longevity in Holstein and Jersey cattle using survival analysis methodology. J. Dairy Sci. 88:804-811. https://doi.org/10.3168/jds .S0022-0302(05)72745-4.

Cole, J. B., and P. M. VanRaden. 2006. Genetic evaluation and best prediction of lactation persistency. J. Dairy Sci. 89:2722-2728. https://doi.org/10.3168/jds.S0022-0302(06)72348-7.

Dobson, H., R. F. Smith, M. D. Royal, C. H. Knight, and I. M. Sheldon. 2007. The high-producing dairy cow and its reproductive performance. Reprod. Domest. Anim. 42(s2):17-23. https://doi.org/ 10.1111/j.1439-0531.2007.00906.x.

Druet, T., F. Jaffrézic, D. Boichard, and V. Ducrocq. 2003. Modeling lactation curves and estimation of genetic parameters for first lactation test-day records of French Holstein cows. J. Dairy Sci. 86:2480-2490. https://doi.org/10.3168/jds.S0022-0302(03)73842 -9 .

Druet, T., F. Jaffrézic, and V. Ducrocq. 2005. Estimation of genetic parameters for test day records of dairy traits in the first three lactations. Genet. Sel. Evol. 37:257. https://doi.org/10.1186/1297 $-9686-37-4-257$.

Haile-Mariam, M., P. J. Bowman, and M. E. Goddard. 2003. Genetic and environmental relationship among calving interval, survival, persistency of milk yield and somatic cell count in dairy cattle. Livest. Prod. Sci. 80:189-200. https://doi.org/10.1016/S0301 -6226(02)00188-4.

Harder, B., J. Bennewitz, D. Hinrichs, and E. Kalm. 2006. Genetic parameters for health traits and their relationship to different persistency traits in German Holstein dairy cattle. J. Dairy Sci. 89:32023212. https://doi.org/10.3168/jds.S0022-0302(06)72595-4.

Jamrozik, J., and L. R. Schaeffer. 2012. Test-day somatic cell score, fat-to-protein ratio and milk yield as indicator traits for sub-clinical mastitis in dairy cattle. J. Anim. Breed. Genet. 129:11-19. https://doi.org/10.1111/j.1439-0388.2011.00929.x.

Koeck, A., F. Miglior, J. Jamrozik, D. F. Kelton, and F. S. Schenkel. 2013. Genetic associations of ketosis and displaced abomasum with milk production traits in early first lactation of Canadian Holsteins. J. Dairy Sci. 96:4688-4696. https://doi.org/10.3168/jds .2012-6408.

Leclerc, H. 2008. Development of the French dairy cattle test-day model genetic evaluation and prospects of using results for herd management. PhD Thesis in Animal Genetics. AgroParisTech, Paris, France.

Leclerc, H., I. Nagy, and V. Ducrocq. 2009. Impact of using reduced rank random regression test-day model on genetic evaluation. Interbull Bull. 40:42-46.

Menéndez-Buxadera, A., A. Molina, F. Arrebola, M. J. Gil, and J. M. Serradilla. 2010. Random regression analysis of milk yield and milk composition in the first and second lactations of MurcianoGranadina goats. J. Dairy Sci. 93:2718-2726. https://doi.org/10 $.3168 /$ jds.2009-2571.
Meyer, K. 2007. WOMBAT-A tool for mixed model analyses in quantitative genetics by restricted maximum likelihood (REML). J. Zhejiang Univ. Sci. B 8:815-821. https://doi.org/10.1631/jzus .2007.B0815.

Mucha, S., R. Mrode, M. Coffey, and J. Conington. 2014. Estimation of genetic parameters for milk yield across lactations in mixedbreed dairy goats. J. Dairy Sci. 97:2455-2461. https://doi.org/10 .3168/jds.2013-7319.

Negussie, E., I. Strandén, and E. A. Mäntysaari. 2013. Genetic associations of test-day fat: protein ratio with milk yield, fertility, and udder health traits in Nordic Red cattle. J. Dairy Sci. 96:1237-1250. https://doi.org/10.3168/jds.2012-5720.

Nishiura, A., O. Sasaki, M. Aihara, H. Takeda, and M. Satoh. 2015. Genetic analysis of fat-to-protein ratio, milk yield and somatic cell score of Holstein cows in Japan in the first three lactations by using a random regression model. Anim. Sci. J. 86:961-969. https:// doi.org/10.1111/asj.12388.

Pryce, J. E., M. D. Royal, P. C. Garnsworthy, and I. L. Mao. 2004. Fertility in the high-producing dairy cow. Livest. Prod. Sci. 86:125-135. https://doi.org/10.1016/S0301-6226(03)00145-3.

Riggio, V., D. O. Maizon, B. Portolano, H. Bovenhuis, and J. A. M. Van Arendonk. 2009. Effect of somatic cell count level on functional longevity in Valle del Belice dairy sheep assessed using survival analysis. J. Dairy Sci. 92:6160-6166. https://doi.org/10.3168/jds .2008-1316.

Rupp, R., V. Clément, A. Piacere, C. Robert-Granié, and E. Manfredi. 2011. Genetic parameters for milk somatic cell score and relationship with production and udder type traits in dairy Alpine and Saanen primiparous goats. J. Dairy Sci. 94:3629-3634. https://doi .org/10.3168/jds.2010-3694.

Schaeffer, L. R. 2016. Random Regression Models. Accessed Jul. 3, 2019. http://animalbiosciences.uoguelph.ca/ lrs/BOOKS/ rrmbook.pdf.

Schaeffer, L. R., and J. Jamrozik. 2008. Random regression models: A longitudinal perspective. J. Anim. Breed. Genet. 125:145-146. https://doi.org/10.1111/j.1439-0388.2008.00748.x.

Sewalem, A., F. Miglior, G. J. Kistemaker, and B. J. Van Doormaal. 2006. Analysis of the relationship between somatic cell score and functional longevity in Canadian dairy cattle. J. Dairy Sci. 89:3609-3614. https://doi.org/10.3168/jds.S0022-0302(06)72400 $-6$.

van der Werf, J. H. J., M. E. Goddard, and K. Meyer. 1998. The use of covariance functions and random regressions for genetic evaluation of milk production based on test day records. J. Dairy Sci. 81:3300-3308. https://doi.org/10.3168/jds.S0022-0302(98)75895 $-3$.

Wiggans, G. R., and G. E. Shook. 1987. A lactation measure of somatic cell count. J. Dairy Sci. 70:2666-2672. https://doi.org/10 $.3168 /$ jds.S0022-0302(87)80337-5.

Zavadilová, L., J. Wolf, M. Štípková, E. Němcová, and J. Jamrozik. 2011. Genetic parameters for somatic cell score in the first three lactations of Czech Holstein and Fleckvieh breeds using a random regression model. Czech J. Anim. Sci. 56:251-260. https://doi.org/ 10.17221/1286-CJAS.

Zumbach, B., S. Tsuruta, I. Misztal, and K. J. Peters. 2008. Use of a test day model for dairy goat milk yield across lactations in Germany. J. Anim. Breed. Genet. 125:160-167. https://doi.org/10 $.1111 /$ j.1439-0388.2007.00718.x.

\section{ORCIDS}

M. Arnal $\odot$ https://orcid.org/0000-0002-2671-5026

H. Leclerc $\odot$ https://orcid.org/0000-0002-2103-2234

V. Ducrocq ๑ https://orcid.org/0000-0002-1503-5199

C. Robert-Granié @ https://orcid.org/0000-0001-5313-2187 